\title{
REFLEXIONES FRENTE A UNA SOCIEDAD PSICOLÓGICAMENTE DESORIENTADA
}

\section{Reflections To A Psychologically Disoriented Society}

\author{
Manuel Arboccó de los Heros \\ Universidad Femenina del Sagrado Corazón, Perú
}

\begin{abstract}
Resumen
A continuación, compilamos un conjunto de ensayos donde reflexionamos críticamente, algunos de los temas más preocupantes de nuestras sociedades posmodernas, tecnocráticas, líquidas, hiperconsumistas y del apuro crónico. Incertidumbre, insatisfacción permanente, desapego, individualismo y relativismo extremo son algunos de los conceptos retratados en este trabajo. Es claro un diagnóstico poco favorable de nuestra sociedad en materia psicológica individual e interpersonal y siendo realistas al reconocer que vivimos tiempos más que inciertos (pandemia por Covid-19 incluida), terminamos este artículo aspirando a un cambio individual y sociofamiliar para intentar salir de esta época de incertidumbres y asperezas sociales. Consideramos, además, que debemos identificar y conocer lo social para comprender luego mejor al yo individual de cada ser humano, no basta ya apelar a un cambio personal cuando la maquinaria social produce males como veremos a continuación. Duele decirlo, pero esta sociedad actual no promueve la salud y eso hay que señalarlo y denunciarlo. Ojalá-lo deseamos de todo corazón- la utopía humanista pueda concretarse de a pocos.
\end{abstract}

Palabras clave. Hiperconsumo, yoísmo, desapego, existencia inauténtica, posmodernidad.

\begin{abstract}
Then, we compile a set of essays where we reflect critically, some of the most troubling subjects of our postmodern, technocratic, liquid, hyper-consumerist and chronic distresssocieties. The uncertainty, permanent dissatisfaction, detachment, individualism and extreme relativism are some of the concepts portrayed in this work. It is clear an unfavourablediagnosis of our society in individual and interpersonal psychological matters and recognizing realistically that we live more than uncertain times (covid-19 pandemic included). We ended this article by aiming for individual and socio-family change to try to rise from this time of uncertainties and social roughness. Moreover, we consider that we must identify and know the social to better understand the individual self of each human being. It is not enough to appeal to a personal change when the social machinery produces evils as we will see below. It hurts to say it but this current society does not promote health and that must be pointed out and denounced. We hope, we wish it wholeheartedly, humanist utopia can be realized slowly.
\end{abstract}

Keywords: Hyper-consumption, selfishness, detachment, inauthentic existence, postmodernity.

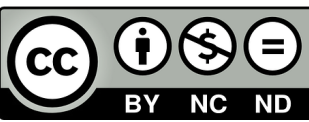

Cualquier uso que se haga de este artículo debe incluir: Autor / Título original de la publicación / ISSN.

\footnotetext{
* Psicólogo. manoloarbocco@gmail.com. https://orcid.org/0000-0002-8481-310X
} 


\section{DESAPEGO, YOÍSMO Y FAMILIA}

\section{La generación del desapego}

Sosteníamos en un trabajo publicado previamente en el Diario El Peruano que desde hace unas tres o cuatro décadas aproximadamente, vemos promociones de niños muy pequeños salir de casa e ir a parar a centros educativos de los más diversos (Arboccó de los Heros, 2017). Como los padres tienen que trabajar y mucho y casi ya no pueden estar en casa (son las reglas de este sistema económico), los hijos sufren de desapego temprano y en vez de vivenciar el concepto de familia, de grupo primario (nosotros lo llamamos el concepto de "manada" como tributo a la orientación etológica y evolucionista) más bien lo que experimentan es una lamentable expulsión rápida del hogar, situación seguramente muy dolorosa también para sus progenitores que deben salir a buscar cómo ganarse la vida. Observamos así niños que muy tempranamente pasan a manos de cuidadores foráneos que no siempre son personas psicológicamente calificadas y si bien muchas de ellas pueden serlo, éstas, no lo olvidemos, no son sus padres, razón quizá por la cual encontramos a muchas personas con problemas para socializar, confiar y comprometerse afectivamente. Son la generación del desapego. Afirma el psicoanalista Marcos Gheiler:

Una de las características del ser humano que lo diferencian de la gran mayoría del resto de animales es la profunda impotencia con la que nace. Es cierto que existen animales, especialmente entre los mamíferos, que requieren de sus madres por un tiempo prolongado, pero en ningún caso por tanto tiempo como en el ser humano. Como consecuencia, el vínculo con otro resulta psicológicamente vital en la existencia humana al punto de que no es posible entender ni definir a una persona si no es en la relación con los demás, así como no es posible describir a un bebé si no es en relación con su madre (Gheiler, 1996; citado por Vélez, 2012, págs. 66-67).

Eduard Punset, escritor y divulgador científico español, nos refería hace algunos años siguiendo el aporte brindado desde las neurociencias, que los niños necesitan amor para desarrollarse y para crecer y que cualquier carencia emocional sufrida deja una huella en ese cerebro infantil determinando al adulto que será después (Punset, 2007). Los niños y niñas necesitan formar e interiorizar tempranamente la idea de familia, de clan, de "manada", de grupo. Eso les da seguridad y confianza. Vivencian así la protección ante cualquier eventualidad, se reconocen como personas que tienen una familia que vela por ellos y los cuida, y a la que se deben también. Pero desde hace algunos años, lo que experimentan las criaturas es la separación temprana -muchas veces dolorosa- del clan familiar. Pasan a manos de terceros que no siempre tienen la vocación ni la preparación para acogerlos, acompañarlos y atenderlos. Algunas voces dirán que es positivo que desde chicos sean independientes y sepan hacer sus cosas, pero los que esto dicen olvidan que una cosa es ser independiente y otra cosa es ser desconfiado, poco sensible, egocéntrico y distante. Trabajos experimentales clásicos en laboratorios psicológicos como los de Mary Ainsworth (1965, 1967, 1978), Harry Harlow (1965), René Spitz (1945, 1965), John Bowlby (1979, 1988, 1995), entre otros, demuestran que muchos niños con apego defectuoso esconden tristeza, rabia y otras deficiencias al vincularse con otras personas. Los niños desde pequeños prestan una atención especial al rostro humano sobre todo al rostro de la madre y, según Giardini "las investigaciones demuestran que los niños que no reciben las atenciones necesarias, o que han sufrido de violencia, son menos precisos al reconocer las emociones con respecto a los que han crecido con afecto y dedicación" (2017, p. 44).

Existen casos donde todo esto no llega a mayores dificultades y los niños se adaptan a estas reglas sin mayor compromiso de suánimoy de su creatividad.Pero otros, solo empiezan a entrenarse en cómo sobrevivir sin querer tanto, pues querer a quien te deja, duele. De ahí que, de grandes, tienen tantas dificultades para confiar y para amar. Surgen así varias posibilidades de vidas inauténticas y neuróticas: personalidades celosas, dependientes, agresivas, carentes de compromisos, poco expresivas y frías sentimentalmente. Pero no es que la gente haya nacido así, sino que experiencias desafortunadas como las señaladas, nos vuelven más vulnerables, más defensivos, menos autónomos y más neuróticos.

No dejemos que el sistema de vida, trabajo y consumo actual nos siga alejando de lo más importante, esto es la familia, es decir, el grupo primario. 


\section{Caducidad del "yoísmo"}

Hay frases que son verdad, porque al final de la frase hay
alguien

Marie Balmary (El monje y la psicoanalista)

El contexto era el siguiente: habían pasado dos guerras mundiales, las religiones dominaban la mente de las personas mucho más que ahora, ellas solían reprimir sus deseos y necesidades individuales por hacer lo que sus padres, la familia, la iglesia, la patria, las costumbres imponían y al final, teníamos personas que no asumían con libertad y responsabilidad sus vidas, sino que vivían según el rígido estándar familiar y cultural de su tiempo. A algunos les resultaba, a otros no y éstos últimos solían ir al diván de algún psicoanalista de la época.

Es así que, pasadas esas épocas de miedo, culpa y represiones, aparecieron los psicólogos, psicoanalistas y psiquiatras y se enfrentaron a esta forma tan limitada de vida. Llegaron las invitaciones a vivir nuestra vida, a pensar por nosotros y en nosotros, y a darnos cuenta de nuestra singularidad "yo soy yo, tú eres tú", "yo soy primero", "tengo derecho a hacer lo que yo necesito", "es mi vida", "yo soy importante", "yo debo amarme", "yo debo pensar en mí" y muchas otras frases se empezaron a ponerse de moda en una sociedad donde el hombre se había colocado en un segundo lugar frente a los imperativos éticos nacionales, religiosos y familiares. $\mathrm{Y}$, pensamos que eso estuvo bien, en ese momento. Pero hoy ya no funcionan más. Hemos abusado de esos "уо quiero...", "уо necesito...", "уо pienso primero en mí...". Por eso hablamos de ese "yoísmo" que observamos en muchos lados y lo entendemos como la tendencia exclusiva a centrarnos en nosotros mismos, solo en nuestras necesidades, puntos de vista y perspectivas (Arboccó de los Heros, 2020).

Por ejemplo, en muchas familias que van al consultorio observamos hijos -tanto adolescentes como jóvenes ya- quienes solo desean hacer lo que quieren y olvidan que también deben cumplir algunas responsabilidades. Los hijos tienen también deberes frente a su hogar, se deben a sus padres mientras estos los acogen en casa y los mantienen. Pero muchos vienen mostrándose como unos engreídos, majaderos y malagradecidos incapaces de actividades cotidianas como limpiar su baño, de preparar alguna vez un desayuno para sus padres o de pagar ellos -ya grandesuna cena familiar en una salida de noche, por señalar algunos ejemplos muy simples. Incapaces, sin iniciativa, esperando siempre recibir y con expresiones como "ellos deben darme y darme", "su deber es mantenerme, yo no pedí nacer", "yo quiero eso y punto", "son mis padres y me tienen que mantener". Comentarios como estos no sirven, no afianzan vínculos, no fortalecen el concepto de familia, en una palabra, no suman, y hoy se escuchan mucho más que hace décadas atrás.

En las escuelas (y hasta en universidades) los jóvenes no quieren obedecer a sus maestros, no desean hacer tareas ni recoger la basura del piso que ellos tiran, "para eso está la que limpia", "es aburrido", "no me molesten", "déjenme en paz", "iqué pesado! más de lo mismo" se escucha hoy. Es probable que muchos sean el modelo de sus propios padres, esos mismos padres que no cumplen sus obligaciones, no pagan las mensualidades asumidas, no cumplen con el Estado, no crían de forma oportuna e inteligente a los hijos que han traído al mundo, siempre atentos "a sacarle la vuelta" a todo lo que se pueda. Hay también centros educativos privados, y esto es preocupante, donde se forma a los muchachos -que ya llegan pensando solo en ellos- bajo una mentalidad de éxito empresarial al más puro estilo egoísta, mercantilista y material. Capitalismo al estilo más bárbaro posible. Pareciera que para algunos los valores sociales, ambientales y éticos son cosas poco importantes y lo que sí se valora es ser un gran emprendedor, tener esa empresa y ser millonario en el menor tiempo posible. Si se contamina el ambiente, se engaña al Estado o no se brindan los salarios justos procurando un buen clima a los empleados y se les respeta, es lo de menos. Esta es la mentalidad posmoderna debilitada moralmente. Estas personas, solo centradas en sí mismo, van a estrellarse con la realidad al final. El mundo ya no soporta más egocéntricos ni narcisistas, necesita gente que sin dejar de lado sus convicciones, sus necesidades y sus deseos, sea capaz de vivir en comunidad, de vivir con otros (sea en una casa, un edificio, una empresa o una escuela). La convivencia es difícil, eso se sabe bien, pero entrar a una relación con la absurda idea que "solo soy importante yo y mis deseos" llevará finalmente al choque más cruel y triste, y quizá a la separación. Hoy vemos jóvenes en cuya escuela 
ya nadie los tolera, igual ocurre en los edificios de departamentos con vecinos impresentables y en otros ambientes respectivamente.

Recordemos a Bretones (2005), cuando diferencia la trascendencia de la inmanencia:

"La logoterapia entiende por trascendencia aquella opción de vida libre, voluntaria y responsablemente elegida, por la cual el hombre sale de sí mismo, no en sentido alienante o escapista, sino que sale al mundo para hacer su vida útil a alguna causa o a alguien. Es lo mismo que sentir la propia vida como algo servicial, como referido a algo o a alguien distinto de uno mismo. Por inmanencia, la logoterapia entiende el movimiento contrario: la permanencia de uno dentro del estrecho y asfixiante recinto de sí mismo, sin proyección de su vida en ninguna dirección. Vivir para sí y nada más que para sí. En la inmanencia no hay sentido referencial y, mucho menos, sentido servicial. Por eso, la inmanencia está en la raíz de toda neurosis y depresión” (op. cit. pág. 36).

García Pintos (2006) señala un sano equilibrio entre esta inmanencia y la trascendencia, cuando precisa que "una persona inmanente, volcada sólo sobre su autorrealización, es una persona que carece del sosiego espiritual que significa la existencia significativa; una persona volcada sólo sobre lo trascendente con indiferencia de lo más íntimo y profundo de su interioridad, desarrolla una existencialidad pseudosignificativa, en tanto su orientación trascendente será un discurso, un andamio, sin base" (p. 194). Pero pareciera que la inmanencia y la búsqueda exacerbada de la propia (y única) autorrealización es el quid del asunto, el objetivo posmoderno en muchas naciones.

Yo soy importante, pero tú también. Hay que invitar también a ver al otro, al compañero valioso, al familiar que nos espera y al cual nos debemos pues nos ama y sí me fijo bien puede ser parte de nuestro bienestar y sentido inclusive (Frankl, 2004). Este yoísmo del que hablamos ya cumplió su propósito, ya caducó. Ya no es útil en estos tiempos que demandan mayor hermandad que nunca. La gente grita en las calles -aquí y allá- por sus libertades, nunca hemos escuchado que salgan a las calles a gritar por sus responsabilidades.
Responsabilidades como padres, hijos, estudiantes, empleados y jefes, autoridades y amigos. Finalmente, responsabilidades como humanos.

Si solo pensamos que somos el ombligo del mundo y que solo importan mis necesidades y mis objetivos, es probable que nos convirtamos en unos narcisistas engreídos insoportables y que nos quedemos solos o que nuestros vínculos sean muy pobres, pues dos egoístas no hacen una pareja ni una familia ni siquiera una empresa.

\section{La normalización de las deficiencias}

Nadie es ladrón, si todos lo son; leíamos alguna vez. Cierto, si bien no es el único, existe un criterio estadístico al hablar de la normalidad (Denegri, 2012). Con base en ello, lo normal se encuentra en lo que hace o le ocurre a la mayoría de la gente; "una persona normal es la que está próxima a la tendencia central de un grupo típico de individuos" (ob. cit. pág. 19). Antes era anormal ser zurdo, que una mujer no tenga esposo e hijos, que un hombre decente llevara aretes o que una señorita se hiciera un tatuaje. Muchas de estas situaciones, vemos hoy, no tienen por qué seguir siendo extrañas, sospechosas de desviación o abiertamente enfermas. Se trata de consecuencias propias del paso de los años y la práctica de nuevas costumbres. Una revisión de conductas que son producto de modas y estilos diversos.

Sin embargo, consideramos que también la comunidad, ha "normalizado" aspectos preocupantes cuando no patológicos. Así, hoy es "normal" entre ciertos grupos de adolescentes y jóvenes, hablar groserías en presencia de adultos y personas mayores; llegar muy tarde a reuniones y eventos de todo tipo; "copiar" en los exámenes universitarios y hasta en tesis universitarias (sin el menor remordimiento); ser pillo (la mal entendida viveza criolla) cada vez que hay oportunidad alguna; actuar de manera informal o de espaldas a la ley, ser corrupto (la triste falacia para justificar el "roba pero hace obra") entre otros ejemplos de "deficiencias normalizadas". Todo lo mencionado es visto hoy como normal. También es casi "normal" (aceptado, común) entre los más jóvenes estar aburrido todo el tiempo o vivir en un vacío existencial, adorar el cuerpo o hasta intimar con cualquiera apenas surja el deseo o se presente la oportunidad ("total, todos 
lo hacen" y "yo hago con mi cuerpo lo que quiero" solemos escuchar y leer en las redes sociales).

Muchas sociedades así "normalizan" vicios, defectos y hasta trastornos. Pues bien, hay que "desnormalizar" el sinsentido, la apatía, la vacuidad, la grosería, la chabacanería y la sandez. Por ejemplo, ciertos conductores, radiales y televisivos, y ahora los muy aclamados "influencers" nos invitan todo el tiempo a hacer concesiones con lo superficial, lo tonto, lo "light". El lingüista Noam Chomsky nos recuerda que una forma de manipular al espectador moderno es estimulando a ser complaciente con la mediocridad, promover al público a creer que es moda el hecho de ser estúpido, vulgar, inculto (Chomsky, 2012).

Nuestras instituciones no siempre cuentan con una buena dosis de salud psicológica y social. Una muestra son los altos niveles de ansiedad, depresión y violencia de todo tipo. En los últimos años, a pesar de las campañas, sigue habiendo más casos de feminicidio y violencia de todo tipo, alcoholismo, las adicciones no disminuyen y hasta sigue aumentando. Los profesionales de la salud y toda la gente buena y decente debe establecer un espacio en los hogares, escuelas, universidades y empresas para conversar de estos temas; resolver dudas entre nosotros mismos y fortalecer el ánimo de las personas. Humanizar las empresas y centros de estudio, elevar el nivel de nuestros medios de comunicación ( $\mathrm{TV}$, radio, prensa, etc.), apostar e invertir en los deportes, actividades artísticas diversas y contribuir en reconstruir así un país más habitable, saludable, seguro; uno menos complaciente con la maldad y el dolor.

\section{HIPERCONSUMO Y ANESTESIA VOLUNTARIA}

\section{Medicalización de la vida}

¿Se han dado cuenta de la inmensa cantidad de gente que lleva fármacos en bolsos y carteras? Pastillas para la tos, para la alergia, para el resfriado común, para dolores de cabeza y por supuesto "para los nervios". Y, existe una próspera industria de psicofármacos, léase ansiolíticos, antidepresivos, antipsicóticos, etc. Desde hace años se les receta fármacos a niños y a jóvenes, algunos de ellos muy potentes y con efectos adversos, peligrosos como el famoso caso del Ritalin o la
Oxycodona por el cual hay hasta demandas judiciales en algunos países.

Se ha medicalizado la vida. Hoy se piensa que cualquier queja o dolor o mal comportamiento es una desviación cuando no una patología. Si un hijo carece de modales y no quiere hacer la tarea, medicina con él; si no presta atención pues medicina también; si no se puede superar la pérdida de un amigo, medicina; si cuesta dormir temprano pues tengo cien cosas en la cabeza propias de un ciudadano de esta sociedad estresada, seguro hay una eficaz medicina; si no aparece el deseo sexual, medicina igualmente. Si no tengo apetito, más medicina y por si acaso otra medicina para combatir la acidez que me generan tantas medicinas.

Ahora, existencialmente hablando, no toda queja o fastidio es señal de una enfermedad, ni siquiera es necesariamente un síntoma en el sentido clínico. Estamos viviendo tiempos donde se piensa que cualquier malestar sea físico, anímico o moral debe ser enfrentado con alguna pastilla de esas que crean los grandes científicos (¿o las corporaciones?) Hemos medicalizado la vida, pues hemos patologizado todo.

Néstor Braunstein, médico y psicoanalista argentino, quien ha escrito sobre el punto, es enfático al señalar que "hay una confrontación sorda y sórdida entre la medicina (pública y privada) y la libertad del sujeto político" (Braunstein, 2013, p. 40).

Desde mediados de los setenta varios especialistas (de la propia medicina) han venido denunciando esta tendencia a institucionalizar el consumo de fármacos para todo y por todo, gente muy conocida en psicología como Ronald Laing, Tomas Szasz, David Cooper figuran como grandes referentes.

En nuestro país, la buena medicina es carísima y los monopolios farmacéuticos fomentan la lenta adicción y el placebo a la cura definitiva, pues un enfermo completamente sanado es un comprador menos. Basta ver por TV esos ridículos comerciales de empresas farmacéuticas donde el adolorido, el enfermo, el paciente entra contento y sale aún más feliz de una farmacia llevando un saco de jarabes, ampollas y grageas. ¿Es creíble eso? No dudamos, 
seríamos necios de hacerlo, que la medicina es necesaria y cuando es recetada de manera correcta, ética y criteriosa nos hará bien. Pero los seres humanos no siempre trabajamos de manera ética y humanista.

\section{Voluntad de anestesiarse}

Se llama anestesia a aquella sustancia que produce una pérdida parcial o total de la sensibilidad. Podría pensarse en un proceso médico quirúrgico al hablar de anestesia y anestesiados, pero la búsqueda de formas alternativas de sedarse, y así dejar de sentir (sobre todo tensión o dolor) son tan antiguas como la civilización misma. Ahora lo vemos claramente en el mundo del alcoholismo y la drogadicción; el consumidor busca anestesiarse, dejar de sentir, olvidar, al menos por un momento aquello que no puede encarar de su vida: sus vergüenzas, sus tristezas, la incertidumbre, el rencor o sus minusvalías.

La venta de analgésicos es un negocio multimillonario. En muchos países los ansiolíticos (junto con los antidepresivos y los antipsicóticos) son recetados y comprados todos los días, adquiridos por personas que, decíamos, no pueden sobrellevar sus tensiones, insomnios, aburrimientos y desasosiego. De ahí que nos hacemos la pregunta, ¿le conviene a la millonaria industria farmacéutica que la gente esté más tranquila, más serena, más feliz? ¡si es precisamente por el desequilibro físico y psíquico que la gente hace colas para la adquisición de químicos con los cuales reducir sus dolencias! Aunque suene contradictorio, económicamente a esta sociedad le parece muy rentable que la gente ande angustiada, en vez de que aprenda a afrontar sus vicisitudes con mayor creatividad existencial, templanza y valentía.

Nos enteramos en la práctica clínica, de chicas jóvenes que se autolesionan, suelen cortarse las manos, las muñecas y las piernas (ahora llamado cutting siguiendo la moda de los términos en inglés) y quienes, al ser consultadas al respecto, señalan sin dudar que de esa forma dejan de sentir el otro dolor, el dolor emocional. Curioso, reemplazan el dolor psicológico, por un dolor físico por ellas mismas infringido.

El psicoanalista austríaco Bruno Bettelheim (19031990), tenía una apreciación de las drogas por demás interesante: para él la droga era la madre instantánea.
Efectivamente, cuando el bebé llora por hambre o alguna incomodidad, la madre al tomarlo entre sus brazos y darle la leche consigue que el pequeño deje inmediatamente de llorar, en ese sentido lo alivia, lo tranquiliza, lo seda. Si recordamos el rostro de un bebé que acaba de tomar su alimento hasta llenarse, reconoceremos en él a un pequeño drogado de ese primer elemento vital, la leche cálida de su madre. Quizá luego, ante la carencia de otros mecanismos -más maduros, saludables e inteligentes- buscaremos un reemplazo postizo de esa madre anestesiadora, ya sea con las drogas, el alcohol, las pastillas o lo que fuese.

$\mathrm{Y}$, al sistema social actual le conviene tener a la gente anestesiada, y para eso no solo nos ofrece sus sedantes, sino que vuelve loca la vida de la gente, con su publicidad, su música, sus noticias y sus valores del mercado. Nos enloquece y al mismo tiempo, nos medica. Negocio redondo. Muy atentos a todo esto.

\section{Sociedad del hiperconsumo}

Giles Lipovetsky, filósofo y sociólogo francés, señala que ya no vivimos tiempos del capitalismo de las élites sino del consumo masivo, se ha generalizado el consumo en todos los grupos sociales, al punto que hoy se habla del hiperconsumo. Por ejemplo, vemos muchos equipos electrónicos en un mismo hogar (en una sola casa hay varios televisores, varios teléfonos hasta varios autos, inclusive). La sociedad del hiperconsumo, dice el francés, busca equipar individuos, ya no a las familias. Esto exacerba el individualismo pues cada quien emplea su equipo en su espacio y en su tiempo, independientemente de la familia y de la compañía (Lipovetsky, 2007).

Los comportamientos del consumo tienen mucho que ver con criterios de clase, advierte el autor. El consumo es, ahora, mucho más ecléctico. Antes las compras estaban ciertamente limitadas dentro del colectivo; lo que se adquiría estaba hasta cierto punto regulado por la clase socio-económica a la que se pertenecía. Hoy las personas compran lo que sea, donde sea, cuando lo desean; a eso, él lo llama individualismo desregulado. No hay marcos, ni barreras; cualquiera puede comprar lo que sea, sin barreras culturales como las tradiciones, convenciones, etc. Pues bien, si el consumidor es cada vez más dependiente del mercado en cuanto a la satisfacción diaria de sus necesidades 
(muchas necesidades creadas por la publicidad) es más difícil escapar de la oferta mercantil en este mundo del placer (el autor habla de un hedonismo instantáneo).

Seguidamente, nos recuerda que la sociedad del hiperconsumo busca un consumo más sensorial, más emocional. Pensemos en esto: no nos ofrecen un jabón, nos prometen belleza; no nos ofrecen una prenda de vestir, nos prometen que con ella tendremos estatus, o placer o amigos. Ya no se vende un viaje sino una experiencia maravillosa. Absurdo sí, pero funciona. La publicidad intensifica el presente en el acto de consumir; para evitar así, la rutina infiernizante de la vida; es el consumo como paliativo a la vida difícil de la gran mayoría de las personas. El consumo es un consuelo de nuestras frustraciones, soledades y fracasos. Y sí, efectivamente el consumo nos hace sentir mejor. El filósofo señala que hoy hay más depresivos que reemplazan la misa antigua con el ir de compras.

Lo que motiva al consumidor es la exaltación de los valores hedonistas, solo se tiene una vida pues no hay que privarse de nada. El mensaje constante del mercado es "goza, date gusto" (recordemos ese mensaje publicitario de una marca de gaseosas que nos sugería "obedece a tu sed"). El hiperconsumo hedonista e instantáneo se ha vuelto legítimo. Todo lo queremos al instante y el mercado no nos hace esperar, nos lo brinda inmediatamente. Y, aparecen las contradicciones pues se valora el consumo, el disfrute, el presente y el placer, pero por otro lado hay un mandato de cuidado de la salud, de prevención. Inclusive, hay un hiperconsumo médico denuncia Lipovetsky; prevención, pólizas, seguros, vitaminas, fármacos y más fármacos. Hoy ya no se trata de curar enfermedades sino de prevenirlas.

Es así como desde mediados del siglo $\mathrm{XX}$ en adelante la compra compulsiva y este hiperconsumo se han asociado mucho a la felicidad. Y esto ya no solamente ocurre en los EEUU sino en Europa y en Latinoamérica. $\mathrm{Al}$ respecto, en su libro La gran estafa de la felicidad, el psicólogo peruano Jorge Yamamoto, nos presenta una mirada alternativa a uno de los conceptos más manoseados como lo es el concepto de la felicidad, manoseado sobre todo en esta época de la posmodernidad donde muchos "gurús del éxito" y "coachs de la vida" suelen prestarse a la complicidad de asociarlo al estatus y la imagen, al consumo, al gasto comercial, a los placeres más inmediatos y efímeros. El autor insiste a lo largo de la obra de acercar la felicidad a los valores sociales, familiares, comunitarios. El cooperativismo, el sentirse apoyado, la compañía y los buenos momentos son más importantes que esta tendencia occidental acumulativa de prendas, artefactos, inmobiliarios, récords y buenas cuentas bancarias; "habíamos encontrado que formar una familia era la mayor fuente de felicidad en los más distintos contextos culturales y de vida" (Yamamoto, 2019 , p. 15). Asimismo, se puede encontrar la idea por la que la cultura actual aumenta la importancia del dinero, la apariencia y el estatus y esto reduce la importancia de la comunidad y de las relaciones humanas. ¿Y cuál es la gran estafa de la felicidad?, el autor concluye que la felicidad per se no es el fin de la vida ni de la sociedad, y esta estafa muy ofrecida por los medios nos lleva a una vida hedonista que termina -cual búmeran paradójico- en infelicidad, ansiedad y depresión, además de vacíos (males posmodernos) y permanente aburrimiento le sumaríamos nosotros. Es decir, la felicidad no es el fin en sí mismo sino la calidad de la vida y las relaciones humanas basadas en la reciprocidad, el cooperativismo y el apoyo a la hora de resolver los problemas, de darse esto la conclusión sería una experiencia de felicidad que se mantendría en el tiempo, así se señala que "en las pequeñas comunidades rurales, la vida cotidiana transcurre en una intensa y permanente relación entre familiares y amigos" (ob. cit. p. 61). Parece pues que la búsqueda de la felicidad es relativamente reciente en la historia, a finales del siglo XVIII -según el autor- "comienza a aparecer la felicidad en la agenda política y a comienzos del siglo XX recién los manuales de crianza iban señalando la importancia de la felicidad del niño" (op. cit. p. 152). Un dato interesante lo encontramos cuando Yamamoto cita a Peter Sterns, para quien la búsqueda de la felicidad "es un fenómeno reciente y de origen estadounidense vinculado con procesos históricos de confort y placer y se relaciona con la mejora de la economía" (ob. cit. p. 153).*

\footnotetext{
* No es el propósito de este artículo versar sobre la felicidad, pero los interesados pueden dirigirse a trabajos como los de Alarcón (2009), Segura y Ramos (2009), Queraltó (2017), Gijón (2017), por citar algunos.
} 
¿Alguna posible solución a este dilema del hiperconsumo? Según algunos especialistas en el tema, como el propio Lipovetsky, se trata de ser un consumidor informado (no caótico ni impulsivo, como quiere el mercado).

\section{Publicidad alienante}

Como refiere la publicidad de una empresa telefónica hoy se ofrece la vida en plan todo ilimitado, pero ¿Qué significa ello?, ¿Qué está detrás de estos mensajes? Veamos, el ser humano requiere aprender tempranamente que no todo es posible, que no todo lo que deseamos puede y/o debe ser conseguido siempre; y que existen situaciones finitas, hay límites a nuestros placeres, a nuestras exigencias, a nuestras posibilidades. Pero es propio de esta época del consumo exagerado y de la promesa de la felicidad asociada a ese consumo, creer -sin fundamentos claro- que nada me debe detener y que todo lo debo conseguir y por supuesto, debo disfrutar como desquiciado pues solo tengo una vida y este es mi momento.

Un comercial de bebidas gaseosas nos decía hace unos años "obedece a tu sed", olvidando que los seres humanos somos criaturas racionales, seres éticos y con criterio, y no podemos obedecer solo a necesidades básicas, no podemos responder a imperativos corporales, sino que debemos asumir nuestro comportamiento producto de una reflexión inteligente en cada situación (Bretones, 2005). Decir "obedece a tu sed" es como proponer "obedece a cualquiera de tus órganos", y sabemos bien que esa "obediencia" puede generarnos más de un problema en la comunidad.

Vivir la vida en plan ilimitado, por contradictorio que parezca, solo consigue generar más insatisfacción, más embotamiento, menos valor al momento vivido o al producto mismo que hoy gozo. Si nuestra vida no estuviera limitada por la muerte daría lo mismo tener 60 o 5000 años; el tiempo carecería de valor y las metas del futuro serían un despropósito pues siempre estaría ahí el futuro, un eterno y agobiante futuro; pero al sabernos cortos, pequeños y temporales, eso funciona como resorte para intentar ahora hacer algo con nuestra vida y aprovechar el tiempo que tenemos, o como dice Bretones (2005) "si se vivencia que la vida es para algo, se sobreentiende que ese accionar siempre debe ser trascendente" (p. 23). Hoy vemos -como resultado de errores educacionales- muchos hijos malagradecidos, impacientes, con cero de tolerancia a la frustración, que consideran que deben recibir todo lo que piden, que deben ser satisfechos todos sus requerimientos y al instante.

Un paquete de uso de internet puede tener la modalidad de todo ilimitado pero la vida no. Los límites a nuestra existencia, pueden ser genéticos, psíquicos, económicos y culturales, lo cual no elimina nuestra libertad personal pero sí reduce su distancia; finalmente asumiremos nuestra libertad y responsabilidad dentro de ese margen que sí disponemos.

Por eso cuando vemos mensajes publicitarios como aquel de "todo ilimitado", pensamos que es una falacia más de la publicidad cotidiana que nos invita a una vida inmanente, consumista, materialista y mecanizada, bajo el disfraz de promover una vida libre, de disfrute genuino y llena de sentido.

\section{Menciona García Pintos:}

Ciertamente, muchas veces no es fácil encontrar respuestas a aquellas circunstancias que la vida nos lleva a vivir. La vida misma es una realidad dinámica, en permanente movimiento y cuando creemos que tenemos todo bajo control, un nuevo movimiento nos desarma lo armado, como cuando una ligera brisa -a veces un ventarrón- nos voltea un castillo de naipes que hemos logrado armar con bastante dificultad. El hombre vive, entonces, en un equilibrio inestable; en realidad vive haciendo equilibrio como el surfista sobre la cresta de la ola. A veces cae, y debe volver a montarse sobre esa enérgica onda que sigue su curso (2006, p. 19).

Un fin de semana nos topamos con este otro mensaje en una conocida cadena de tiendas, decía: "nuestro compromiso es satisfacción garantizada siempre". ¿Se da cuenta estimado lector? Y, eso solo consigue -nuevamente, de forma paradójica- mayor y permanente insatisfacción, la cual se intentará vanamente de eliminar con la siguiente compra y con la nueva promesa de una vida satisfecha e ilimitada, por siempre. No es casual que en nuestras sociedades posmodernas los índices de depresión, vacío, adicciones y angustia sean tan elevados. Baggini, nos 
dice "Si creemos que en el futuro habrá una vida sin dificultades y preocupaciones estamos equivocados. Necesitamos reconocer la fragilidad de la buena fortuna y la impermanencia de las cosas. Pero, ¿tenemos el valor y la honradez de aceptar la vida tal como es y sacar de ella el máximo provecho? ¿O tenemos que si lo hacemos resultará decepcionante?" nos pregunta el autor (2005, p. 47).

\section{VACUIDAD E IMPOTENCIA}

\section{Sobre el vacío existencial}

¿Por qué hablamos tanto ahora de la sensación de vacío ante la vida? ¿Por qué tantas personas, incluso los jóvenes, suelen sentirse constantemente aburridos, desmotivados, apáticos? A propósito, un síntoma del vacío existencial es el constante aburrimiento (Frankl, 2004).

En este artículo estamos señalando que implica vivir en esta sociedad con sus estilos de vida y de relaciones, propias de estos tiempos postmodernos. El filósofo y sociólogo polaco de origen judío Zygmunt Bauman (1925-2017) -quien acuñara el concepto de modernidad líquida para referirse a sociedades globales, capitalistas, hipertecnológicas, y de muchos cambios sociales desde los años 60 aproximadamenteen su libro Vida de consumo, propone que las personas nos hemos vuelto una masa de consumidores engañados, seducidos, arrastrados y manipulados todo el tiempo por la publicidad. Inclusive nuestros vínculos están variando violentamente, al respecto Bauman menciona: "los clientes habituales de las agencias de citas por internet, engolosinados por las prácticas del mercado, no se sienten nada cómodos en compañía de seres humanos de carne y hueso. El tipo de productos con los que fueron entrenados para socializar son para el tacto, pero no tienen manos para tocar" (Bauman, 2007 , p. 31). En este mundo cibernético y ya de robots de pronto las relaciones humanas cálidas están debilitándose, estando como estamos todo el día conectado a máquinas y aplicaciones, vamos perdiendo ese sabor humano que es parte importante del sentido de la vida. "El encuentro con una persona viva requiere de habilidades sociales de las que uno puede carecer o que pueden resultar inadecuadas, y entablar un diálogo siempre implica exponerse a lo desconocido", indica el filósofo (op. cit. p. 32).
Además de los vínculos, los amigos, la pareja, la familia, otra de las maneras de encontrar sentido es el trabajo, nuestra forma de entregar u ofrecer algo valioso a los demás. Pero hoy ya no se nos estimula a ser productores y creativos sino a ser solo objetos de consumo permanente. De esto ya había hablado Erich Fromm en su famoso texto El arte de amar. Bauman también lo precisa cuando en su obra mencionada líneas arriba señala: "La sociedad de consumidores implica un tipo de sociedad que promueve, alienta o refuerza la elección de un estilo y una estrategia de vida consumista, y que desaprueba toda opción cultural alternativa; una sociedad en la cual amoldarse a los preceptos de la cultura del consumo y ceñirse estrictamente a ellos es, a todos los efectos prácticos, la única elección unánimemente aprobada." (Bauman, 2007, p. 78).

El filósofo Lipovetsky, en la misma línea nos invita a reflexionar si estos tiempos venideros no son oportunos para el desenfreno, el exceso, pero también para la apatía, la indiferencia y el vacío. En su famosa obra La era del vacío: ensayos sobre el individualismo contemporáneo, señala al inicio a manera de presentación del ensayo: "El individualismo hedonista y personalizado se ha vuelto legítimo y ya no encuentra oposición; dicho de otro modo, la era de la revolución, del escándalo, de la esperanza futurista, inseparable del modernismo, ha concluido. La sociedad posmoderna es aquella en que reina la indiferencia de masa, donde domina el sentimiento de reiteración y estancamiento, en que la autonomía privada no se discute, donde lo nuevo se acoge con lo antiguo, donde se banaliza la innovación" (Lipovetsky, 2000, p. 9). Y, seguidamente afirma: "Ya ninguna ideología política es capaz de entusiasmar a las masas, la sociedad posmoderna no tiene ídolo ni tabú, ni tan sólo imagen gloriosa de sí misma, ningún proyecto histórico movilizador, estamos ya regidos por el vacío, un vacío que no comporta, sin embargo, ni tragedia ni apocalipsis" (op. cit. p. 9-10).

Frankl, intentó bosquejar una posible causa de estos niveles cada vez más alarmantes de vacío, señalaba por ejemplo que hemos perdido algunas situaciones que rodearon la vida humana desde hace miles de años y que servían para regularlas, a saber, hemos perdido nuestros rituales o tradiciones. Importantísimo tener 
pues estas tradiciones o costumbres sean familiares, regionales o nacionales, pero en esta liquidez de la actualidad van "diluyéndose a pasos agigantados" recalca Frankl (2004, p. 150). Igualmente, menciona en su texto "Ante el vacío existencial", lo siguiente:

Cuando se me pregunta cómo explico la génesis de este vacío existencial, suelo ofrecer la siguiente fórmula abreviada: contrariamente al animal, el hombre carece de instintos que le digan lo que tiene que hacer $\mathrm{y}$, a diferencia de los hombres del pasado, el hombre actual ya no tiene tradiciones que le digan lo que debe de ser. Entonces, ignorando lo que tiene que hacer e ignorando también lo que debe ser, parece que muchas veces ya no sabe tampoco lo que quiere en el fondo. Y entonces sólo quiere lo que los demás hacen (conformismo) o bien, sólo hacer lo que los otros quieren, lo que quieren de él (totalitarismo). Pero estas dos secuelas no deben inducirnos a pasar por alto una tercera. Me refiero a un neuroticismo específico, a saber, la presencia de lo que he designado como "neurosis noógena". Al contrario que la neurosis en sentido estricto, que presenta, por definición, una enfermedad psicógena, la neurosis noógena no se debe a complejos y conflictos en el sentido tradicional, sino a conflictos de consciencia, a colisiones de valores y por último, pero no menos importante, a una frustración existencial que algunas veces puede expresarse bajo la forma de sintomatología neurótica (Frankl, 2008, págs. 11-12).

Consideramos que es necesario saber que hay tiempos -como los que estamos viviendo- $y$ lugares como nuestras sociedades "modernas" que pueden propiciar un mayor vacío, con sus mensajes, propuestas y modas, muchas veces deshumanizantes, superficiales, alienadas y materialistas. Y, es nuestro deber, pensar, denunciar estas prácticas que no permiten vivir en armonía, bienestar y crecimiento.

Finalmente, Loaiza indica que lo que necesitan las mujeres y hombres de hoy es "comprometerse, empeñarse en algo digno de tal compromiso, la entrega a una tarea por la que se puedan decidir libremente" (Loaiza, 2005, p. 258). Además, coincidimos con ella cuando afirma que el sentido de vida "es una construcción que tiene mucha fuerza e importancia en la etapa de la juventud porque, entre tantas razones, coincide con el descubrimiento de su capacidad de amar, con su formación universitaria y con su capacidad de ofrecerse al mercado laboral" (op. cit. p. 259). Tengamos todo esto presente.

Vacuidad e impotencia: ¿Qué hacer frente a ello?

Rollo May (1909-1994), fue un destacado psicólogo y psicoterapeuta estadounidense representante de la línea humanístico-existencial. En uno de sus más famosos libros, titulado "Amor $y$ voluntad", trata, entre otros puntos, el caso de la vacuidad o sensación de vacío que ya se hacía sentir de manera casi dramática en los sesenta. Afirma: "Podrá sorprender el hecho de que, basándome en mi propia práctica clínica y en la de colegas psicólogos y psiquiatras, diga que el principal problema de la gente a mediados del siglo XX es la vacuidad. Mientras uno podía reírse del insignificante tedio que sentía la gente hace una o dos décadas, la vacuidad en muchos casos ha pasado de un estado de aburrimiento o tedio a un estado de futilidad y desesperación que promete peligros" (2011, p. 28). Futilidad es aquello que carece de importancia y esto se ve presente desde entonces en mucha gente que no termina de darle un sentido y un rumbo a sus vidas.

Más adelante el autor nos dice: "el ser humano no puede vivir durante mucho tiempo en una condición de vacuidad: si no tiende activamente hacia algo no sólo se estanca, sino que sus potencialidades se hacen morbosas y se convierten en desesperación que puede culminar en actividades destructivas. La sensación de vacuidad o vacío generalmente se debe a que las personas sienten que son IMPOTENTES para hacer algo efectivo de sus vidas o para hacer algo efectivo en el mundo en que viven." (op. cit. p. 28). Es decir, la sensación de estancamiento, impotencia, inutilidad termina por derribar la voluntad humana y esto entraña peligro al ser posible causa de males como la violencia, las adicciones y las depresiones.

Junto a Rollo May, otros grandes pensadores como Erich Fromm (1900-1980) o Viktor Frankl (19051997), se habían percatado de esto mismo. Fromm, señalaba por entonces que a menos que pertenezca 
a algo, a menos que su vida posea algo de sentido y dirección, el hombre se sentirá como una partícula de polvo y se verá aplastado por la insignificancia de su individualidad; y Frankl advertía igualmente que más que nunca, las personas actuales están experimentando sus vidas como vacías, faltas de sentido, sin propósito, sin objetivo alguno. Todo esto no debe verse como cosa de unos cuantos, de casos individuales y aislados por atender desde la mirada médico psiquiátrica, sino como fenómenos psicológicos que ocurren dentro de épocas y contextos que los hacen más posibles. Así, May nos presenta este libro suyo afirmando algo sobre nuestros sistemas y sociedades que debemos tener en cuenta: "En nuestros días lo curioso respecto al amor y la voluntad es el hecho de que, mientras en el pasado fueron siempre considerados como la RESPUESTA a las dificultades de la vida, ahora se han convertido ellos mismos en PROBLEMAS. Claro está que el amor y la voluntad resultan siempre más difíciles de ejercitar en una época de transición, y la nuestra es una edad de radical transición. Los antiguos mitos y símbolos mediante los cuales NOS ORIENTÁBAMOS han desaparecido y la ansiedad es general y profunda." (op. cit. p. 15); fíjense en el parecido al final con lo que hace años mencionaba Frankl sobre los rituales y tradiciones. Incluso encontramos en esa misma línea al filósofo contemporáneo Chul Han cuando en su libro "La desaparición de los rituales" propone, entre otras cosas, que los rituales sociales hagan por un momento que nos olvidemos de nosotros mismos para pasar a participar con los demás, en ese sentido aleja el narcisismo y ayuda en la identidad (Han, 2020).

En el consultorio vemos con cierta frecuencia mucha gente -sobre todo jóvenes- que no terminan de darle un sentido y un rumbo a sus vidas siendo esto peligroso al dejarlos más vulnerables a las manipulaciones, a las adicciones, a la violencia y ciertos cuadros psicopatológicos. Incluso hoy se reportan casos de autolesiones y crímenes que responden -según sus propios autores han confesadoa hechos realizados por aburrimiento o por matar el tiempo solamente.

La sensación de vacuidad, dicen los expertos, generalmente se manifiesta cuando las personas sienten que son impotentes para hacer algo efectivo de sus vidas o para hacer algo efectivo en el mundo en que viven. Sentir que no puedo hacer nada significativo con mi vida o que no puedo tampoco hacer con ella algo positivo para mí y para otros -construir- nos desanima y amarga. De entre todas las necesidades humanas estudiadas por Erich Fromm, Carl Rogers, Henry Murray o Abraham Maslow, las necesidades de trascendencia, de orientación, de aprecio, de identidad, de autorrealización son fundamentales para convertirnos en seres humanos plenos. Carecer de la posibilidad de ellas, empobrece la voluntad y los afectos y paraliza o desorienta al hombre en su camino al crecimiento humano.

Además, se observa la dificultad o incapacidad para valorar (captar lo valioso) y disfrutar aspectos importantes de la vida humana, por ejemplo, la amistad, las posibilidades del arte, el amor familiar, la educación, los deportes y demás divertimentos que la vida ofrece. Estamos ciegos ante aquello que es agradable, significativo, valioso e importante. La cultura del consumo, del exceso y del embotamiento, de la inmediatez y a la vez de la caducidad en la que nos movemos ahora no brinda las condiciones psicológicamente más favorables para desarrollarnos correctamente; es la "Sociedad del cansancio" como la llama el filósofo surcoreano Byung-Chul Han (Han, 2012). Confundidos e hipnotizados por las propagandas, las modas y las redes cómo andamos últimamente, somos más vulnerables a esta vacuidad, impotencia y esterilidad. Fromm, nos advertía cuando señalaba: "Hoy nos encontramos con personas que obran y sienten como si fueran autómatas; que no experimentan nunca nada que sea verdaderamente suyo; que se siente a sí mismas totalmente tal como creen que se las considera; cuya sonrisa artificial ha reemplazado a la verdadera risa; cuya charla insignificante ha sustituido el lenguaje comunicativo" (Fromm, 1964, p. 21).

Junto a los vínculos, los amigos, la pareja, la familia, otra de las maneras de encontrar sentido es el trabajo, nuestra forma de entregar u ofrecer algo valioso a los demás (Frankl, 2012, 2014). Pero hoy ya no se nos estimula a ser productores y creativos sino a ser solo objetos de consumo permanente, estamos en lo que el francés Lipovetsky llama el hiperconsumismo (Lipovetsky, 2000, 2007). 
Una vida vacía, sin rumbo, deambula existencialmente hablando. Luego de pensar en esto, sigamos algún propósito, pongámonos alguna meta, reconsideremos devolverle la importancia a lo verdaderamente importante y elijamos disfrutar la vida, al menos lo agradable que puede haber en ella.

\section{UNA APUESTA POR LA RAZÓN, LA BONDAD Y LA MORAL}

\section{La gente buena es invisible}

Los medios de comunicación nacional, en especial la televisión, suelen brindarnos durante la primera hora de la mañana lo peor del ser humano, el lado más maligno, salvaje, brutal de nuestra especie. Los noticieros matutinos nos dan de desayunar básicamente asesinatos, asaltos, accidentes graves, violaciones y golpizas brutales con una naturalidad tal que, efectivamente, podemos llegar a considerar al ser humano como la especie más malvada y egoísta de la Tierra. Parecen confirmarnos eso de que el hombre es el lobo del hombre. Solemos pensar que esta forma de seleccionar y ofrecer noticias no hace más que ensuciar la psique de la gente.

Parece que la sensibilidad, el buen gusto y el balance escasean en los noticieros y hay muy poco espacio para la obra de caridad, para el estudiante galardonado, el deportista medallero o el policía honesto, para el médico empático o el docente capacitado y sacrificado. Eso no vende, no hay espacio ni demostración.

Si se fijan bien, es casi el mismo esquema en casi todos los canales. Los noticieros nos abren la mañana -y nos acompañan por la noche, vaya forma de ir a dormir- siempre entregando primero los atracos, extorsiones, actos de corrupción, crímenes e injusticias durante la primera parte de su edición; luego todo lo protervo va acompañado por un buen tiempo para la farándula (trivialidades, tonterías), algo de deporte (también trivializado como una prolongación de los espectáculos) y para finalizar algunas noticias pintorescas que no pasan de ser anécdotas insignificantes al puro estilo de vea el gato que saluda a su dueño, hombre se baña en aguas heladas del río tal o sensacional perro que usa patines sorprende al mundo. Razón tenía Noam Chomsky, mente ilustrada, cuando decía que los medios mantenían al público distraído, "lejos de los verdaderos problemas sociales, cautivada (la gente) por temas sin importancia real. Mantener al público ocupado, ocupado, ocupado, sin ningún tiempo para pensar; de vuelta a la granja como los otros animales..." (Chomsky, 2012).

Pues bien, esta es la realidad televisiva nacional, pero olvidan los que así nos (des)informan que hay mucha gente buena en el país. Hay personas nobles, decentes, honradas, que intentan hacer las cosas bien, gente trabajadora, sacrificada que, a pesar de las dificultades e injusticias vistas por todos, no hacen pactos con lo inmoral, sino que siguen para adelante y hasta buscando ser agentes de cambio. ¿Por qué estos noticieros no asumen un compromiso nacional para mostrar situaciones más positivas, casos de compatriotas que trabajan honradamente, estudiantes que aman su carrera, deportistas que creen en el fair play y consiguen triunfos a puro esfuerzo, empresarios decentes y médicos amables? ¿Por qué tanta atracción por el dolor y la zozobra? Hay gente muy buena en el país, pero es invisible en los medios, más espacio tienen el dolor, el crimen, el escándalo, la parodia del éxito postmoderno y las tonterías de los "realities".

\section{Estos tiempos de pandemia}

La única manera de continuar en la vida es manteniendo templada la cuerda de nuestro espíritu tenso el arco, apuntando hacia el futuro Julio Ramón Ribeyro (Prosas apátridas)

En marzo del año pasado la Organización Mundial de la Salud (OMS), declaró que la situación ya por todos conocida del Covid-19 era una pandemia y desde entonces venimos experimentando una serie de graves consecuencias no solo médicas sino psicológicas y sociales (Balluerka Lasa y cols, 2020).

Estamos en una situación atípica, rara, insólita. Vivir una pandemia no es algo frecuente. Un nuevo virus -el COVID 19-, nos ha puesto "contra las cuerdas" como dicen en el boxeo, nos ha hecho más visibles nuestras limitaciones y eso exige de todos nosotros un cambio en las rutinas, una nueva distribución de recursos y de nuestro tiempo, 
realizar algunas modificaciones, así como pequeños y grandes esfuerzos. Empresas paralizadas, colegios y universidades haciendo maniobras para cumplir el servicio educativo, negocios en pausa y un sistema de salud al tope cuando no colapsado se viene viviendo desde más de un año.

Estos tiempos de aislamiento social y pandemia que vivimos nos llevan a reformularnos algunas cosas; como el manejo de nuestro tiempo (quizá corto para los que siguen trabajando en casa, quizá largo larguísimo- para los que no tienen mucho que hacer en ella); el aspecto relacional familiar y amical (quizá alejados de ciertas personas o de pronto muy cerca de otras -con lo que eso también puede generar, desde la cálida cercanía e intimidad hasta el cansancio, los malentendidos y las discusiones-); el tema del dinero y los sueldos pues conocido es el golpe a la economía general que produce un período de pausa cuando no del complicado cese por la propia naturaleza del trabajo en sí de cada quien. Así, algunas familias se vienen viendo fuertemente mermadas en los ingresos mensuales debiendo tomar decisiones muy complicadas y si bien el gobierno y las propias empresas están haciendo sus esfuerzos, sabemos que ya la vida no es igual en muchos casos. También está el tema de nuestro propio cuerpo y su cuidado y percepción, nuestra corporalidad hoy limitada en su desplazamiento, en su consumo y gasto de energía y en su actividad motora física.

Esta pandemia trae ya las reflexiones de una pluralidad de voces, vemos economistas, abogados, médicos, psicólogos y psiquiatras quienes desde su campo comparten información, sugerencias y advertencias. Todo nos invita a la retención domiciliaria con miras a una protección tanto individual como colectiva. Y, todo nos hace pensar en un concepto clave por estos tiempos: la ADAPTACIÓN. Adaptación y flexibilidad, dos características de las personas que, por lo general, siempre ayudan a manejar contingencias adversas y que son parte de eso que por estos tiempos se identifica como resiliencia, esto es la capacidad de enfrentar adecuadamente la vida a pesar de las adversidades y penurias experimentadas. No debe entenderse como resignación o como una actitud pasiva y claudicante sino por el contrario, orientada más a una adaptación creativa y funcional, proactiva. Nos parece muy curioso, dicho sea de paso, la experiencia de encierro (sentirse encerrado en casa) que hemos escuchado en varias personas; pues en casa bien podríamos sentirnos seguros, tranquilos, pero ¿encerrados? De pronto las dimensiones del hogar, la cantidad de miembros, el equipamiento y servicios en cantidad y calidad, las relaciones particulares con algunos y el estado psicológico de otros pueden, efectivamente, que algunos se sientan así encerrados.

Según la investigación dirigida en la Universidad del País Vasco por Balluerka Lasa "las personas encuestadas han empeorado en prácticamente todas las variables analizadas" (2020, p. 126), así los niveles de irritabilidad, ansiedad, percepción de vulnerabilidad y miedo al futuro se han elevado, como también se han presentado cambios en los patrones de sueño y de alimentación, problemas de convivencia, depresión e incluso ideación suicida. También llama la atención que los resultados refieran que la población más afectada son las mujeres, las personas que viven solas, los migrantes y las personas mayores y con algunas enfermedades físicas y mentales. Y, en el Perú tras el estudio titulado Salud mental en sobrevivientes a la Covid-19 de un hospital general (publicado en el Diario El Comercio, 17 de enero del 2020) presentado por un equipo de médicos psiquiatras del Hospital Guillermo Almenara liderado por Jeff HuarcayaVictoria, se encontró que una proporción significativa de los pacientes presentan síntomas depresivos $(30,3 \%)$, ansiosos $(29,9 \%)$, somáticos $(33,7 \%)$ y de distrés $(28,7 \%)$. Algunas de las variables señaladas en el artículo que también influyen en el menor ajuste ante la pandemia son la mayor vulnerabilidad femenina a la depresión y la ansiedad, el lugar de procedencia (vivir fuera de Lima nos hace más propensos a cargas de estrés), haber tenido familiares infectados o fallecidos por la Covid-19 y el nivel de severidad de la propia infección en cada quién.

Esta época de pandemia es un nuevo momento donde la salud psíquica de la población se pone otra vez a prueba. Las personalidades más bien rígidas, antisociales, obsesivas o narcisistas probablemente verán aumentados sus niveles de ansiedad, de rabia y de tristeza. La rigidez es lo opuesto de la flexibilidad como la intransigencia de la tolerancia y entender que esto tomará un tiempo, quizá de unos meses o de pronto de otro año más, hasta que volvamos a las 
actividades de costumbre puede ser más sencillo para algunas personas que para otras.

Organizarse, anticiparse, prever, saber postergar algunos placeres o caprichos, serenarse, son cualidades que hoy valen mucho más que antes. Además de intentar vivir pacíficamente y no actuar solo de manera egoísta. Tener un "Plan B" y hasta un "Plan C" es lo más recomendable pues parece que tenemos aislamiento y cuarentena para rato. El gobierno ha repetido hasta el cansancio que si toda la población respetara las indicaciones pasaríamos más rápido esta difícil situación; el mensaje es claro y fácil de entender; pero este desorden e indisciplina vista en algunos peruanos y extranjeros demuestra una vez más los problemas mentales, comportamentales y morales que tenemos como sociedad. Los otros virus, tan agresivos como el COVID-19, son la negligencia, la indolencia, la indisciplina, el egoísmo y la terquedad y para esos virus no hay tratamiento inmediato, no hay cuarentena que ayude.

Los especialistas en cuestión, entiéndase infectólogos, biólogos, epidemiólogos, han brindado ya la información necesaria para evitar el contagio y, en caso éste sea inevitable, han comunicado cómo sobrellevar el proceso viral. Demostremos pues civismo, responsabilidad y empatía y respetemos las indicaciones esperando pase el "pico" de contagio y se inicie el proceso de vacunación. Usemos la creatividad y la imaginación para ver como invertimos este tiempo disponible junto a la familia.

\section{CONCLUSIONES:}

1. No dejemos que el sistema de vida, trabajo y consumo actual nos siga alejando de lo más importante, esto es la familia, el grupo primario.

2. Este yoísmo del que hablamos anteriormente ya cumplió su propósito, ya caducó. Ya no es útil en estos tiempos que demandan mayor hermandad que nunca. La vida invita a la trascendencia más que a la inmanencia, el sentido de vida está afuera (con los otros) más que en un encierro solipsista.
3. Nuestras instituciones no siempre cuentan con una buena dosis de salud psicológica y social. Los profesionales de la salud y todas las personas buenas y decentes deben establecer un espacio en los hogares, las escuelas, las universidades y las empresas para conversar de estos temas; resolver dudas entre nosotros mismos y fortalecer el ánimo de nuestra gente.

4. La cultura actual aumenta la importancia del dinero, la apariencia, el consumo exacerbado y el estatus y esto reduce la importancia de la comunidad y de las relaciones humanas cálidas y empáticas.

5. Las personas nos hemos vuelto una masa de consumidores engañados, seducidos, arrastrados y manipulados todo el tiempo por la publicidad. Inclusive nuestros vínculos están variando violentamente.

6. Más que el consumo exagerado y la lucha descontrolada por el estatus son las relaciones humanas basadas en la reciprocidad, el cooperativismo y el apoyo a la hora de resolver los problemas lo que parece que conduce a la felicidad. Además de los vínculos, los amigos, la pareja, la familia, otra de las maneras de encontrar sentido es el trabajo, nuestra forma de entregar u ofrecer algo valioso a los demás. Pero hoy ya no se nos estimula a ser productores y creativos sino a ser solo objetos de consumo permanente, por eso atentos a eso.

7. No es casual que en nuestras sociedades posmodernas los índices de depresión, vacío, adicciones y angustia sean tan elevados.

8. Consideramos que es necesario saber que hay tiempos -como los que estamos viviendo- y lugares como nuestras sociedades "posmodernas" que pueden propiciar un mayor vacío, con sus mensajes, propuestas y modas, muchas veces deshumanizantes, superficiales, alienadas y materialistas. Y, es nuestro deber como profesionales de la Psicología, pensar, denunciar estas prácticas que no nos permiten vivir en armonía, bienestar y crecimiento.

9. Es urgente humanizar las empresas y centros de estudio, elevar el nivel de nuestros medios de comunicación ( $\mathrm{TV}$, radio, prensa), apostar 
e invertir en los deportes y las expresiones artísticas diversas y contribuir así en hacer del país uno más vivible, más saludable, más inteligente; uno menos complaciente con la maldad y el dolor. Desde donde nos estemos debemos sumar a estos objetivos.

10. Estos tiempos de aislamiento social y pandemia que vivimos nos llevan a reformularnos algunas cosas. Organizarse, anticiparse, prever, saber postergar algunos placeres o caprichos, serenarse, son cualidades que hoy valen mucho más que antes. Además de intentar vivir pacíficamente y no actuar solo de manera egoísta.

\section{REFERENCIAS}

Alarcón, R. (2009). Psicología de la felicidad. Universidad Ricardo Palma.

Arboccó de los Heros, M. (2020). Tiempos inciertos: aproximaciones a la sociedad posmoderna. Atenhea.

Arboccó de los Heros, M. (26 de junio del 2017). La generación del desapego. Diario Oficial El Peruano.

Baggini, J. (2005). El sentido de la vida. Y las respuestas de la Filosofía. Urano.

Balluerka Lasa, N. y cols. (2020). Las consecuencias psicológicas de la Covid-19 y el confinamento. Informe de investigación. Universidad del País Vasco.

Bauman, Z. (2007). Vida de consumo. Fondo de Cultura Económica.

Braunstein, N. (2013). Clasificar en psiquiatría. Biblioteca Nueva.

Bretones, F. (2005). Logoterapia: apelación a la vida como tarea. San Pablo.

Chomsky, N. (20 de mayo de 2012). Manipulación mediática. Facebook. http:// www.facebook.com/permalink.php?story fbid $=223780137725527 \& \mathrm{id}=170310603072481$

Han, B. (2012). La sociedad del cansancio. Herder.
Han, B. (2020). La desaparición de los rituales. Herder.

Denegri, M.A. (2012). Normalidad y anormalidad $y$ el asesino desorganizado. Universidad Inca Garcilaso de la Vega.

Diario El Comercio (17 de enero del 2020). Vivir en estado de depresión. Informe. Suplemento El Dominical. Págs. 12-13. Jorge Paredes Laos (periodista). Publicado el domingo 17 de enero del 2020.

Frankl, V. (2012). Psicoterapia y humanismo ¿Tiene un sentido la vida? Fondo de Cultura Económica.

Frankl, V. (2008). Ante el vacío existencial. Hacia una humanización de la psicoterapia. Herder.

Frankl, V. (2004). El hombre en busca de sentido. Herder.

Fromm, E. (1964). Psicoanálisis de la Sociedad Contemporánea. Hacia una sociedad sana $\left(6^{\mathrm{a}}\right.$. ed.). Fondo de Cultura Económica.

García Pintos, C. (2006). Cita a ciegas. Sobre la imprevisibilidad de la vida. San Pablo.

Giardini, A. (2017). Paul Ekman. Las emociones y las expresiones. Colección Comprende la Psicología. Salvat.

Gijón, V. (2017). La percepción del profesorado sobre la felicidad [Tesis de doctorado]. Universidad de Granada.

Lipovestky, G. (2000). La era del vacío. Ensayos sobre el individualismo contemporáneo. Décimotercera edición. Anagrama.

Lipovestky, G. (2007). Lafelicidad paradójica. Ensayo sobre la sociedad de hiperconsumo. Anagrama.

Loaiza, O. (2005). Construcción del sentido de vida en jóvenes universitarias [Tesis de doctorado]. Universidad Iberoamericana.

May, R. (2011). Amor y voluntad. Contra la violencia y la apatía en la sociedad actual. Cap. 1: Nuestro mundo esquizoide.Gedisa.

Punset, E. (2007). El viaje del amor. Destino.

Queraltó, P. (2017). Felicidad personal y felicidad social en la obra de Julián Marías [Tesis de doctorado]. Universidad de Barcelona. 
Segura, M. y Ramos, V. (2009). Psicología de la felicidad. Avances en Psicología, 17(1). Universidad Femenina del Sagrado Corazón.

Vélez, O. (2012). La educación desde el psicoanálisis. La función analítica del educador. Universidad Peruana de Ciencias aplicadas (UPC).
Yamamoto, J. (2019). La gran estafa de la felicidad. Paidós.

Fecha de recepción: 14 de enero 2021

Fecha de aceptación: 22 de abril 2021 